\title{
EDITORIAL
}

\section{Nonlinear Dynamics and Navigating the End of Life}

\author{
Lou Lukas, $M D^{1,2}$ \\ 'Veterans Health Administration, Nebraska and Western Iowa, Omaha, Nebraska \\ ${ }^{2}$ Division of Geriatrics, Gerontology, and Palliative Medicine, Department of Medicine, University of Nebraska Medical Center, Omaha \\ Nebraska
}

Ann Fam Med 2020;18:484-485. https://doi.org/10.1370/afm.2612.

A s a family physician who migrated to the practice of palliative medicine, I've spent the past 20 years pondering the rules American medical culture observes regarding the way people die, and the role of physicians in that final transition. Culture is a nonlinear system where the tension between creatively adapting to unexpected challenges and coping with the tedious boredom of mechanistic certainty are delicately balanced. Add more control and the system becomes stultifyingly rigid, while less restraint can send the system spinning into anarchy and chaos. Small perturbations can have dramatic consequences, and slight modification of the rules can determine whether the system flourishes or decays.

As the only child of an 84-year-old woman, I totally understood the allure of the opportunity for a relatively quick, controlled, and painless death described in "The Foresty Way."1 My mom has survived 2 bouts of cancer and the deaths of her husband, all her siblings, and most of her closest friends. She does not want to live through another serious illness. Once, when I was doing my palliative duty of asking about her preferences for life-sustaining treatment should she become suddenly critically ill, she quipped, "Oh, honey, just shoot me. I don't want to be a sick old lady."

There is a compelling argument that medical aid in dying should be legal, safe, and rare. But, after watching medical culture evolve for even the few decades of my practice, I worry about altering the rules we have observed about physician participation in hastening death. When the rules are too tight, people suffer, leaving scars that affect surviving generations, but

Conflicts of interest: author reports none.

\section{CORRESPONDING AUTHOR}

Lou Lukas, MD

Veterans Administration, Nebraska and Western Iowa 4101 Woolworth Ave \#4199

Omaha, NE 68105

lou.lukas@gmail.com too few constraints could tip the delicate balance into dystopian territory. Finding the just-right solution will take time and careful consideration.

For a quick tour of dystopia, consider this: in a system where most doctors are employed by large health care systems that are increasingly conscious of the costs incurred on behalf of the sick and the frail, how long will it take for before medical aid in dying becomes the path to a better bottom line? Having watched how events as momentous as the right to vote and space travel went from revolutionary to mundane in just a few decades, I fear not long enough. It isn't hard to imagine the direct-to-consumer advertising campaign: "Your children don't need to watch you suffer. With the Compassionate Cocktail you can take charge of your death," (while conveniently easing the health care system's budgetary woes). The health system doesn't even need to promote it. People might choose assisted dying because there is no one to care for them as their body fails, or they feel the burden on their families would be to great. Even with the Medicare hospice benefit, few families can afford unpaid leave to care for an elder, the cost of a residential hospice, or the price of a home health aide that would make natural, gradual death a compassionate possibility.

Leaving dystopia behind, I worry that if a quick, controlled death is too easy we may forsake the vital lessons that come at the end of life, the opportunities to practice compassionate presence and acquire the deep wisdom and courage that accrues when the ego relinquishes its tight-fisted attempts to control the eternal tides of human life and death. People may trade what is left of their lives not for relief of actual, immediate suffering, but to alleviate the fear of future suffering and the anxiety of anticipating their impending death. Though it is more painful for some than others, existential distress is nearly ubiquitous for those who are not mystics or lifelong meditators; in fact, you could argue it is this anxiety which fuels the "prolongist" tendencies of medicine. Physicians have had few tools to address this form of suffering, but 
solutions may be on the horizon. Emerging research reports that patients with life-threatening cancers have rapid and sustained relief of depression, anxiety, and demoralization after a single intervention consisting of brief supportive counseling and one monitored session of high-dose psilocybin, a classic psychedelic drug. ${ }^{2,3}$ After being diagnosed with stage III lung cancer in 2013, Kerry Pappas entered a trial at Johns Hopkins. Five years later, shortly after learning that she had new brain metastases, she told her story on "60 Minutes."4 Smiling, she described the lasting effects of her psilocybin experience: "It's amazing dying doesn't frighten me. Living doesn't frighten me... "When Anderson Cooper asked if it make her happier, she responded, "I don't necessarily use the word 'happy.' Comfortable, like, [hugging herself] comfortable. I've suffered from anxiety my whole life. I'm comfortable, I can die. I mean, it's huge. It's huge!"

Yes, 5 years after a single intervention, she was still able to face the prospect of dying with equanimity, even in the face of advancing disease, and her results were not exceptional. A follow-up study of the NYU cohort found that the effects persisted in up to $80 \%$ of participants 4.5 years later, and almost all the survivors rated the session one of the most spiritually meaningful events in their lives. ${ }^{5}$ Unfortunately, physicians have had no legal access to psilocybin since the late 1960 's when it was swept into Schedule I of the Controlled Substances Act. It is tragically ironic that there is a movement to empower physicians to use their medical licenses to prescribe legally available medication with the explicit intention of ending a patient's life while we have no legal access to a drug that may restore their ability to live comfortably through a terminal diagnosis.

Primum non nocere (first, do no harm) is a rule that has guided medical practice, albeit imperfectly, for centuries. While there may be instances where prescribing medications to end a patient's life may truly be the best of bad options, we should first work to change the rules, policies, and practices that lead to the suffering that causes people to seek a hastened death.

To read or post commentaries in response to this article, see it online at https://www.AnnFamMed.org/content/18/6/484.

Key words: end of life; physician-assisted dying; medical aid in dying; psychedelics

Submitted September 15, 2020; accepted September 21, 2020.

\section{References}

1. Handley M. The "foresty way": my mother's brave choice of medical aid in dying. Ann Fam Med. 2020;18(6):553-554.

2. Griffiths RR, Johnson MW, Carducci MA, et al. Psilocybin produces substantial and sustained decreases in depression and anxiety in patients with life-threatening cancer: a randomized double-blind trial. J Psychopharmacol. 2016;30(12):1181-1197.

3. Ross S, Bossis A, Guss J, et al. Rapid and sustained symptom reduction following psilocybin treatment for anxiety and depression in patients with life-threatening cancer: a randomized controlled trial. J Psychopharmacol. 2016;30(12):1165-1180.

4. Researchers experimenting with psychedelics to treat addiction, depression and anxiety. 60 Minutes. CBS Television. Oct 13, 2019. Accessed Dec 2020. https://www.cbs.com/shows/60_minutes/video/ aVr4a9j7Sa5PhkHjhaE_e5QIMoU4WaX/researchers-experimentingwith-psychedelics-to-treat-addiction-depression-and-anxiety/

5. Agin-Liebes GI, Malone T, Yalch MM, et al. Long-term follow-up of psilocybin-assisted psychotherapy for psychiatric and existential distress in patients with life-threatening cancer. J Psychopharmacol. 2020;34(2):155-166.

\section{CORRECTION}

Ann Fam Med 2020;18:485. https://doi.org/10.1370/afm.2617.

In Chang T, Ravi N, Plegue MA, Sonneville KR, Davis MM. Inadequate hydration, BMI, and obesity among US adults: NHANES 2009-2012. Ann Fam Med. 2016;14:320-324, the numbers in the last 2 rows of Table 2 (Bivariate Relationships Between Hydration Status and Participant's Characteristics) were inadvertently switched. The correct values are as follows:

\begin{tabular}{lcc}
\hline Characteristic & Adequately Hydrated & Inadequately Hydrated \\
\hline Obese, \% & 32.2 & 40.3 \\
Non-obese, \% & 67.7 & 59.7 \\
The authors regret the error. & \\
\hline
\end{tabular}

